\title{
Erratum to: Effects of low-level laser therapy applied before or after plyometric exercise on muscle damage markers: randomized, double-blind, placebo-controlled trial
}

Carolina Gassen Fritsch $^{1}$ • Maurício Pinto Dornelles ${ }^{1} \cdot$ Lucas Severo-Silveira $^{1}$.

Vanessa Bernardes Marques ${ }^{1}$. Isabele de Albuquerque Rosso ${ }^{1}$.

Bruno Manfredini Baroni ${ }^{1}$

Published online: 1 December 2016

(C) Springer-Verlag London 2016

Erratum to: Lasers Med Sci (2016) 31:1935-1942

DOI 10.1007/s10103-016-2072-y

The published online version contains mistake. The wavelength of the laser equipment used in this study is $850 \mathrm{~nm}$ (and not $810 \mathrm{~nm}$, as stated in the article).

The online version of the original article can be found at http://dx.doi. org/10.1007/s10103-016-2072-y.

Bruno Manfredini Baroni bmbaroni@yahoo.com.br

Carolina Gassen Fritsch carol.fritsch@hotmail.com

Maurício Pinto Dornelles mauriciodornelles@gmail.com

Lucas Severo-Silveira severo.fisio@gmail.com

Vanessa Bernardes Marques nessa.bmarques@gmail.com

Isabele de Albuquerque Rosso isabellearosso@gmail.com

Physiotherapy Department, Universidade Federal de Ciências da Saúde de Porto Alegre, Rua Sarmento Leite, 245, Porto

Alegre, RS90050-170, Brasil 